\title{
Development of an RNA Expression Platform Controlled by Viral Internal Ribosome Entry Sites ${ }^{\mathbb{}}$
}

\author{
Hae Li Ko ${ }^{1 \dagger}$, Hyo-Jung Park $^{1 \dagger}$, Jihye Kim², Ha Kim ${ }^{3}$, Hyewon Youn ${ }^{3,4}$, and Jae-Hwan Nam ${ }^{1 *}$ \\ ${ }^{1}$ Department of Biotechnology, The Catholic University of Korea, Bucheon 14662, Republic of Korea \\ ${ }^{2}$ Department of Medical Nutrition, Graduate School of East-West Medical Science, Kyung Hee University, Yongin 17104, Republic of Korea \\ ${ }^{3}$ Cancer Imaging Center; Seoul National University Hospital, Seoul 08826, Republic of Korea \\ ${ }^{4}$ Department of Nuclear Medicine, Cancer Research Institute, Seoul National University College of Medicine, Seoul 08826, Republic of Korea
}

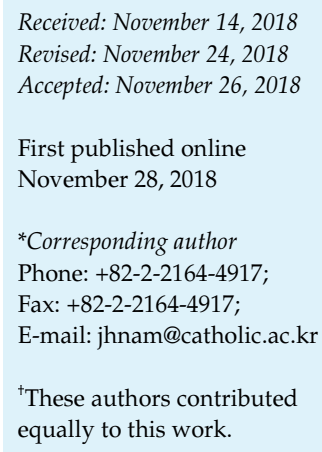

S upplementary data for this paper are available on-line only at http://jmb.or.kr.

pISSN 1017-7825, eISSN 1738-8872

Copyright(C) 2019 by

The Korean Society for Microbiology and Biotechnology
Since 1990, many nucleic acid expression platforms consisting of DNA or RNA have been developed. However, although RNA expression platforms have been relatively neglected, several such platforms capped at the $5^{\prime}$ end of RNA by an anti-reverse cap analog have now been developed. At the same time, the capping reaction is a bottleneck in the production of such platforms, with high cost and low efficiency. Here, we investigated several viral and eukaryotic internal ribosome entry sites (IRESs) to develop an optimal RNA expression platform, because IRES-dependent translation does not require a capping step. RNA expression platforms constructed with IRESs from the $5^{\prime}$ untranslated regions of the encephalomyocarditis virus (EMCV) and the intergenic region of the cricket paralysis virus (CrPV) showed sufficient expression efficiency compared with cap-dependent RNA expression platforms. However, eukaryotic IRESs exhibited a lower viral IRES expression efficiency. Interestingly, the addition of a poly(A) sequence to the $5^{\prime}$ end of the coxsackievirus B3 (CVB3) IRES (pMA-CVB3) increased the expression level compared with the CVB3 IRES without poly(A) (pCVB3). Therefore, we developed two multiexpression platforms (termed pMA-CVB3-EMCV and pCrPV-EMCV) by combining the IRESs of CVB3, CrPV, and EMCV in a single-RNA backbone. The pMA-CVB3-EMCV-derived RNA platform showed the highest expression level. Moreover, it clearly exhibited expression in mouse muscles in vivo. These RNA expression platforms prepared using viral IRESs will be useful in developing potential RNA-based prophylactic or therapeutic vaccines, because they have better expression efficiency and do not need a capping step.

Keywords: Internal ribosome entry sites, RNA expression platform, coxsackievirus B3, cricket paralysis virus, encephalomyocarditis virus, poly(A)

\section{Introduction}

In 1990, Wolff et al. first showed that the direct injection of nucleic acids (DNA or RNA) into mice could lead to the expression of a gene of interest (GOI) in muscle tissues [1]. Thus, the creation of an expression platform using DNA or RNA is possible because the direct injection of such nucleic acids containing a GOI results in the expression of GOIencoded proteins in vivo and induces specific immune responses, such as antibodies and cytotoxic T cells, against
GOI-encoded proteins [2, 3]. Many articles have reported the generation of DNA expression platforms since then [2, 4]. However, RNA expression platforms appear to have been neglected because of the difficulties in RNA production via in vitro transcription and in RNA handling, because of degradation by ubiquitous RNases [5]. Some companies and research groups have now developed RNA platforms that express GOIs [3, 4, 6, 7]. In fact, RNA expression platforms have many advantages. First, they have a high degree of safety because they do not require 
nuclear entry and host chromosomal integration; they lack an antibiotic gene, thus avoiding antibiotic resistance; and they show a paradoxically fast degradation, thus avoiding the immunotoxicity caused by repeated injections. Second, they show convenient production in vitro because of the lack of any need for unnecessary biological processes, such as mass cell culture and live pathogen culture, thereby escaping the requirement for biological facilities such as bioreactors. Third, they afford a well-balanced induction of immune responses, such as T-helper cell 1 (Th1) and Th2 activation, as well as humoral and cellular responses because of the characteristic ability of RNAs to activate innate immune pathways [2-6, 8-10]. These features are advantageous for the production of prophylactic vaccines. However, and paradoxically, they are disadvantageous for the development of therapeutic vaccines, because the activation of the innate immune response can prevent RNA expression $[2,3,8]$.

Based on these advantages, the RNA expression platforms developed to date are of two types: self-replicon RNA platforms that use an alphavirus backbone, and conventional non-replicon RNA platforms that use cap-dependent translation [10]. However, although self-replicon RNA platforms can amplify the resultant RNA-the repliconthere are safety concerns about the remaining viral backbone, as it is composed of virus-derived nonstructural proteins such as those from arboviruses, the La Crosse virus, and alphavirus nsP2, which are involved in the evasion of the innate immune responses as interferon antagonists [11-13]. In contrast, non-replicon-based conventional RNA platforms are conceptually identical to eukaryotic mRNA $[2,3,9,10]$. Thus, they require capping, which is the addition of a guanine amino acid methylated at the 7th position at the 5' end of RNA via an anti-reverse cap analog (ARCA) reaction. This is necessary to protect against RNA degradation and increase RNA translation efficiency [10]. However, performing the ARCA reaction in vitro is very expensive and has low efficiency; thus, this creates a bottleneck for the commercial mass production of RNA expression platforms.

In contrast to cap-dependent "scanning" translation, a cap-independent mode of translation initiation is found in many viral genomes and even in some cellular genes [14]. This translation initiation can recognize directly the fold of the $5^{\prime}$ untranslated region (5' UTR) of RNAs by ribosomes and eukaryotic initiation factors. This folding region is called the internal ribosome entry site (IRES) $[15,16]$. The concept of using an IRES as an alternative to a capdependent translation scanning model was first introduced in 1988 for a picornavirus [4, 17]. Since then, several structural characterizations and molecular functions have been revealed [14-16, 18]. Viral IRESs are divided into four classes based on the molecular folding structure of the RNA and the mode of action of translation, such as that involving canonical eukaryotic initiation factors (eIFs) or specific stimulatory IRES trans-acting factors [15, 16, 18]. Class I IRESs require most translational initiation factors, with the exception of eIF4E, recruit the $40 \mathrm{~S}$ ribosome complex as in the canonical scanning model, and are found in Picornaviridae such as coxsackievirus B3 (CVB3). Class II IRESs initiate translation directly at start codons without any scanning at the $5^{\prime}$ end of RNA sequences; they require most eIFs, as is the case in class I IRESs, and are found in some Picornaviridae such as the encephalomyocarditis virus (EMCV). Class III IRESs also initiate translation directly at start codons by recognizing RNA fold structures-such as pseudoknots-without scanning but require fewer eIFs than do class I and II IRESs and are found in Flaviviridae such as the Japanese encephalitis virus (JEV). Class IV IRESs have a simple translational mode that does not require any eIFs: it involves only the elongation factor 2 to stabilize translocation intermediates [15, 19] and has some complicated RNA folding structures. Interestingly, in contrast with other IRESs, which are generally located in the 5' UTR of RNA sequences, class IV IRESs are found in intergenic regions (IGRs) of Dicistrovoridae such as the cricket paralysis virus (CrPV) [15, 16, 18]. Moreover, IRESdependent translation does not require the ARCA capping step. Therefore, an IRES RNA expression platform can escape the capping step that is necessary for conventional RNA expression platforms.

In this study, we investigated GOI expression efficiency in five viral IRESs: those of CVB3 (class I), EMCV (class II), JEV (class III), CrPV (class IV), and the Sindbis virus (SV) (unassigned class); as well as three cellular IRESs: those of the eukaryotic initiation factor $4 \mathrm{G}$ (eIF4G), fragile X mental retardation 1 (FMR1), and connexin 43 (CN43). All IRESdependent RNA expression platforms were synthesized with multicloning restriction enzyme sites (MCSs). The Renilla luciferase $(\mathrm{R} / \mathrm{L})$ or firefly luciferase $(\mathrm{F} / \mathrm{L})$ genes were inserted into an MCS of each RNA expression platform and luciferase expression levels were measured to compare the expression efficiency of each platform in several cell lines, including human A204 and mouse Nor10 muscle fibroblasts and human 293T embryonic kidney cells, and in mouse muscle in vivo. An RNA expression platform with cap-dependent translation was synthesized according to a published patent protocol and was used as a 
positive control [7]. We found that some viral IRES platforms showed better or similar expression efficiency compared with the control cap-dependent expression platform. These expression platforms do not require the capping step, thereby avoiding the bottleneck in the mass production of RNA expression platforms and potentially enabling the development of RNA-based prophylactic or therapeutic vaccines.

\section{Materials and Methods}

\section{Design and Synthesis of IRES Expression Platforms and Cloning with Reporter Genes}

To compare the efficiencies of various virus- and cell-derived IRES-dependent translation systems, we selected and designed an IRES expression RNA platform using the viral IRES 5' UTR and 3' UTR with 50 adenylates at the $3^{\prime}$ end of the $3^{\prime}$ UTR (SV, CVB3, EMCV, JEV, eIF4G, FMR, and CN43), with the exception of pCrPV, which was used in the IGR IRES sequence instead of the $5^{\prime}$ UTR, and an SV40 late-polyadenylation signal sequence was used instead of the 3' UTR and poly(A). Our RNA platform had an MCS with four restriction enzyme sequences between UTRs, to enable the insertion of the reporter genes $\mathrm{R} / \mathrm{L}$ and $\mathrm{F} / \mathrm{L}$. We used the RNA platform developed by CureVac (pCAP-ribosome) as the positive-control platform.

To confirm the effect of VPg of CVB3 on IRES activity and increase in translation efficiency, we designed another type of platform containing 50 adenosine monophosphate residues (poly(A), indicated as MA) at the $5^{\prime}$ terminus of the RNA sequence (pMACVB3, pMA-CrPV, and pMA-CN43-R/L), instead of VPg.

To develop our multi-RNA expression platform, which combined two different viral IRESs in one RNA expression platform, we designed pMA-CVB3-MCS1-EMCV-MCS2 and pCrPV-MCS1EMCV-MCS2. First, we inserted the same reporter gene, R/L, under the control of both viral IRESs, pMA-CVB3-R/L-EMCV-R/L and $\mathrm{pCrPV}-\mathrm{R} / \mathrm{L}-\mathrm{EMCV}-\mathrm{R} / \mathrm{L}$, to compare the expression level with that of pCAP-ribosome-R/L, which was used as a canonical cap-dependent translation platform. To investigate the activity of each IRES in our multi-RNA expression platform, we inserted the $\mathrm{R} / \mathrm{L}$ gene under the control of the IRESs of CrPV and MA-CVB3 and the F/L gene under the control of the IRES of EMCV (pMACVB3-R/L-EMCV-F/L and pCrPV-R/L-EMCV-F/L), to compare the levels of expression of different reporter genes by single and multi-RNA expression platforms. All IRES expression RNA platforms were synthesized by Genolution. The sequence information is depicted in Fig. S1.

The Renilla luciferase coding sequence was amplified using forward and reverse primers that covered the restriction site for the insertion of the MCS into each RNA platform. The GOIs were inserted into the MCS of the RNA platform using restriction endonucleases (New England Biolabs, USA). Escherichia coli DH5 $\alpha$-competent cells were used for plasmid preparation, and all plasmid clones were checked by restriction mapping and direct DNA sequencing (Cosmo Genetech, Korea). Transfection-grade plasmids were obtained using LaboPass Plasmid Mini Purification Kits, according to the manufacturer's instructions (Cosmo Genetech).

\section{In Vitro Transcription}

In vitro transcription was performed using the Ribomax Largescale RNA Production System T7 (Promega, USA), which uses the T7 promoter for transcription. The pCVB3-R/L, pJEV-R/L, and pCAP-ribosome-R/L plasmids, which undergo cap-dependent translation, were treated with the ARCA reaction (see below) for capping at the $5^{\prime}$ ends of RNA sequences after in vitro transcription. For in vitro transcription, all platforms were linearized with Not I. Transcription reactions contained $3 \mu \mathrm{g}$ of Not I-cut plasmid DNA, T7 transcription buffer $(5 \times), 25 \mathrm{mM} \mathrm{rNTP}$, nuclease-free water, and T7 enzyme mix and were incubated for $4 \mathrm{~h}$ at $37^{\circ} \mathrm{C}$. For capped transcripts, 40 mM 3'-O-Me-m7G (5')ppp(5')G ARCA was included, and the concentration of rGTP was decreased to $3 \mathrm{mM}$. The transcripts were incubated with $1 \mu$ of RNase-free DNase I (Promega) per $1 \mu \mathrm{g}$ of plasmid DNA for $15 \mathrm{~min}$ at $37^{\circ} \mathrm{C}$, followed by termination of the reaction by incubation at $65^{\circ} \mathrm{C}$ for $10 \mathrm{~min}$. DNase I treatment (Promega) was always performed to remove any DNA contamination during RNA purification using highyield RNA ultra-purification kits (RBC, Taiwan), according to the manufacturer's instructions. DNA and RNA purity and concentration were evaluated using a NanoDrop-2000 spectrophotometer (Thermo Fisher Scientific, USA).

\section{Cell Lines and Culture Conditions}

Human A204 rhabdomyosarcoma cells, mouse Nor10 muscle fibroblasts, and human 293T embryonic kidney cells were obtained from the Korean Cell Line Bank (Korea). A204 cells were maintained in McCoy's 5A medium (Gibco, Thermo Fisher Scientific) supplemented with 10\% fetal bovine serum (FBS; Gibco) and 1\% antibiotics (AAs, Gibco). Nor10 and 293T cells were maintained in Dulbecco's Modified Eagle's Medium (Hyclone, GE Healthcare, UK) containing $10 \%$ FBS and $1 \%$ AAs. All cells were maintained in a humidified atmosphere at $37^{\circ} \mathrm{C}$ with $5 \% \mathrm{CO}_{2}$.

\section{RNA Transfection and Measuring of Reporter Gene Expression in Cells In Vitro}

For luciferase assays, aliquots of $2 \times 10^{5}$ cells were seeded in 48 well plates and cultured at $37^{\circ} \mathrm{C}$ for $24 \mathrm{~h}$, followed by replacement of the medium with medium lacking FBS before transfection. Cells were transfected at $80 \%-90 \%$ confluence using lipofectamine 2000 (Invitrogen, Thermo Fisher Scientific) transfection reagent, according to the manufacturer's instructions. In the assays, $500 \mathrm{ng}$ of RNA (R/L), 5 ng of plasmid DNA (F/L, from Prof. Yoon HW, Medical Center, Seoul University), and $1.25 \mu \mathrm{g}$ of lipofectamine were mixed with $50 \mu \mathrm{l}$ of Opti-MEM medium (Gibco) per well and incubated at room temperature for $5 \mathrm{~min}$. Subsequently, diluted RNA and DNA were mixed with diluted lipofectamine, incubated at room temperature for $15 \mathrm{~min}$, and cotransfected into a prepared 
48-well plate. In addition, $1 \mathrm{ug}$ of a control green fluorescent protein plasmid was introduced, to normalize transfection efficiency. Cells were harvested $24 \mathrm{~h}$ after transfection, and luciferase assays were carried out using a dual-luciferase assay (Promega). All reagents were prepared as described by the manufacturer. The $5 \times$ passive lysis buffer (PLB) was supplied by the manufacturer and used for cell lysis, as described in the "Results" section. Briefly, cells were resuspended in $80 \mu \mathrm{l} /$ well of $1 \times$ PLB. After allowing lysis for $15 \mathrm{~min}, 20 \mu \mathrm{l}$ of each lysate was transferred to a 96-well white assay plate (Corning Costar Corp., USA) and measurements were performed using a Glomax Discover system (Promega). An aliquot of $100 \mu \mathrm{l}$ of firefly luciferase reagent (LAR II) was added to the test sample and luminescence was measured; this was followed by the addition of $100 \mu \mathrm{l}$ of Renilla luciferase reagent and firefly luciferase quenching reagent (Stop \& Glo; Promega), to measure luminescence with an integration time of $10 \mathrm{sec}$. The data are reported as the ratio of Firefly to Renilla luciferase activity. This ratio was generated from the results of the control gene (pCAP-ribosome-R/L) divided by those obtained from the other RNA platforms. Results are presented as the mean relative light units and the standard deviations (SDs) of at least three independent repeats.

\section{Animal Housing, RNA Injection, and Measurement of Reporter Gene Expression In Vivo}

Female BALB/c mice (6 weeks of age, 20-25 g) were purchased from Dae-Han Biolink (Korea) and acclimatized for 1 week. Mouse experiments were performed in accordance with the relevant ethical guidelines and regulations established by the Korean Association for Laboratory Animals [20]. All mice were housed in specific-pathogen-free conditions with a standard light cycle (12 h light/dark) and maintained according to protocols approved by the Institutional Animal Care and Use Committee, Sungsim Campus, Catholic University of Korea. All mice were fed a normal fat $(5 \%)$ diet (Harlan Laboratories, USA) and sterile water. Before injection, protamine sulfate was diluted with distilled water, mixed with each RNA expression platform, and vortexed at room temperature for $5 \mathrm{~min}$. Aliquots of $20 \mu \mathrm{g}$ of the RNA expression platforms mixed with or without protamine were injected intramuscularly into the back muscle of mice. Twenty-four hours after the injection, $15 \mu \mathrm{g}$ of Renilla luciferase substrate (PerkinElmer, USA) was injected intravenously into the tail, and the mice were imaged according to the manufacturer's instructions (PerkinElmer). The IVIS 100 Imaging System (PerkinElmer), which includes an optical charge-coupled device camera mounted on a light specimen chamber, was used for animal data acquisition and analysis. The substrate of luciferase ( $3 \mathrm{mg} /$ mouse) was injected intraperitoneally $10 \mathrm{~min}$ before obtaining in vivo images.

\section{Statistical Analysis}

To assess the statistical significance of differences in luciferase activity and mRNA expression levels between the various treatment groups, the results were analyzed using the KruskalWallis test, followed by the Bonferroni post-hoc test for comparing multiple groups. Two-tailed $p$-values $<0.05$ were considered statistically significant. Data are expressed as the mean \pm SD. Statistical analysis of the data was performed using SAS software (v, 9.4; SAS Institute, Cary, USA).

\section{Results}

Eight Single-RNA Expression Platforms and Two MultiRNA Expression Platforms are Synthesized with Multiple Cloning Sites

To compare the translation efficiency of various viraland cell-derived IRES-dependent systems, we selected four viral IRESs (class I (CVB3), class II (EMCV), class III (JEV), and class IV (CrPV)), as well as three cellular IRESs derived from eIF4G, FMR, and CN43 cells, as described previously [14]. The SV IRES (unassigned) was also selected for virally-derived, cap-dependent translation. We selected

Table 1. List of Viral IRESes.

\begin{tabular}{|c|c|c|c|c|c|}
\hline $\begin{array}{c}\text { RNA } \\
\text { platform }\end{array}$ & $\begin{array}{c}\text { Virus } \\
\text { (Genus) }\end{array}$ & $\begin{array}{c}\text { 5'UTR } \\
\text { (nucleotide number) }\end{array}$ & Multi cloning site (MCS) & $\begin{array}{c}\text { 3' UTR } \\
\text { (nucleotide number) }\end{array}$ & $\begin{array}{c}\text { Accession } \\
\text { number }\end{array}$ \\
\hline pSV & $\begin{array}{l}\text { Sindbis virus } \\
\text { (Togaviridae/Alphavirus) }\end{array}$ & $1 \sim 59$ & BamHI-EcoRV-SacI-EcoRI & $11385 \sim 11703$ & KT121726 \\
\hline pCVB3 & $\begin{array}{l}\text { Coxsackievirus B3 } \\
\text { (Picornaviridae/Enterovirus) }\end{array}$ & $\begin{array}{l}1 \sim 742 \\
+ \text { ATG GCA GCT CAA }\end{array}$ & SalI-EcoRV-SacII-PvuI & 7298 7400 & U57056 \\
\hline pEMCV & $\begin{array}{l}\text { Encephalomyocarditis virus } \\
\text { (Picornaviridae/Cardiovirus) }\end{array}$ & $1 \sim 833$ & BamHI-SacII-SalI-PvuI & $7713 \sim 7835$ & M81861.1 \\
\hline pJEV & $\begin{array}{l}\text { Japanese encephalitis virus } \\
\text { (Flavivirus) }\end{array}$ & $1 \sim 95$ & BamHI--EcoRV-SaII-PvuI & $10392 \sim 10977$ & KU323483 \\
\hline pCrPV & $\begin{array}{l}\text { Cricket paralysis virus } \\
\text { (Dicistroviridae/Cripavirus) }\end{array}$ & $\begin{array}{l}\text { 6025 6213 } \\
\text { (IGR IRES) } \\
+ \text { CCT GCT }\end{array}$ & BamHI-EcoRI-PacI-SacI & $\begin{array}{l}\text { 1535 1755 } \\
\text { (SV40 } \\
\text { late polyadenylation } \\
\text { signal sequence) }\end{array}$ & AF218039 \\
\hline
\end{tabular}


Table 2. List of cellular IRESes.

\begin{tabular}{clcccc}
\hline $\begin{array}{c}\text { RNA } \\
\text { platform }\end{array}$ & \multicolumn{1}{c}{ Gene product } & $\begin{array}{c}5^{\prime} \text { UTR } \\
\text { (nucleotide number) }\end{array}$ & Multi cloning site (MCS) & $\begin{array}{c}3^{\prime} \text { UTR } \\
\text { (nucleotide number) }\end{array}$ & $\begin{array}{c}\text { Accession } \\
\text { number }\end{array}$ \\
\hline peIF4G & Eukaryotic Initiation Factor 4G & $58 \sim 377$ & BamHI-SacI-SacII-NarI & $4571 \sim 5026$ & NM004953 \\
pFMR1 & fragile X mental retardation 1 & $995 \sim 1315$ & BamHI-SacI-SacII-NarI & $43128 \sim 43644$ & NG007529 \\
pCN43 & Connexin43 & $1 \sim 157$ & BamHI-SacI-SacII-NarI & $1893 \sim 2229$ & X52947 \\
\hline
\end{tabular}

5' UTR and 3' UTR sequences from each virus and each cellular gene and placed an MCS with four restriction enzyme sequences between these UTRs, to insert the two luciferase reporter genes (R/L and F/L). All RNA expression platforms were transcribed by $\mathrm{T} 7$ polymerase and contained a poly(A) tail with 50 adenylates at the 3' end of the 3' UTR, with the exception of the CrPV platform, which had an SV40 late-polyadenylation signal instead of the poly(A) tail. As a positive control for the RNA expression platform, we selected a system (called pCAP-ribosome here) developed by the CureVac Co. (Tübingen, Germany) that has cap-dependent translation. It always reacts with ARCA for capping at the $5^{\prime}$ end of RNA sequences after in vitro transcription. The sequence information was obtained from an open source [7]. Detailed information on these RNA expression platforms is given in Tables 1-3 and Fig. S1, which show the allocated GenBank accession numbers and sequences. Using the sequences depicted in Fig. S1, all platforms were synthesized by a commercial company (Genolution, Korea).

Viral IRES-Dependent RNA Platforms Show Expression Efficiencies that are Better Than, or Similar to, that of a cap-Dependent RNA Platform

The R/L gene was inserted into an MCS sequence in the viral RNA expression platforms and RNAs were prepared by in vitro transcription; pCAP-CVB3-R/L-, pCAP-JEV-R/ $\mathrm{L}-$, and $\mathrm{p}$-CAP-ribosome-R/L-derived RNAs were treated with an ARCA reaction for capping. All RNAs were transfected into A204 and 293T cells at the same time and compared with $\mathrm{R} / \mathrm{L}$ expression levels at the appropriate time (see the "Materials and Methods" section for details). The details of all constructed plasmids are provided in Fig. 1A.
We found that EMCV IRES (pEMCV-R/L) had a better expression efficiency than did the cap-dependent expression platform (pCAP-ribosome-R/L) in both A204 and 293T cells at all times after transfection (Figs. $1 B$ and $1 C$ ). The system with the second-highest expression efficiency was CrPV IRES (pCrPV-R/L), which was lower than that of pEMCV-R/L but showed a slightly lower or similar expression pattern compared with $\mathrm{pCAP}$-ribosome-R/L, depending on cell type and time of expression (Figs. 1B and 1C). Taken together, the results of this experiment suggest that RNA expression platforms controlled by viral IRESs, especially those from the EMCV 5' UTR and CrPV IGR, are not inferior to cap-dependent RNA expression platforms, at least when compared with the commercially developed pCAP-ribosome-R/L expression system.

\section{Cellular IRES-Dependent RNA Platforms Show Lower Expression Levels than Does the cap-Dependent RNA Platform}

We selected IRESs bearing three cellular genes (CN43, eIF4G, and FMR1) to compare translation efficiencies based on a previous article [14]. That study showed that the eukaryotic initiation factor 4G (eIF4G)-derived IRES yielded a very high expression level, even 500 times higher than the EMCV IRES, in KB-3-1 cells (a subclone of HeLa cells) [21]. The fragile $X$ mental retardation 1 (FMR1) gene encodes an RNA-binding protein [22] and its mutation is involved in fragile $X$ syndrome and participates in noncoding RNA pathways [23]. The connexin43 (CN43)-derived IRES has 208 nucleotides and is included in one of the gap junction proteins [24]. Thus, this gene can be expressed continuously in cells, suggesting that the CN43-derived IRES might have a high translation efficiency. Therefore, we synthesized each cellular IRES gene with MCSs and inserted the R/L

Table 3. List of multi-RNA expression platforms.

\begin{tabular}{ll}
\hline \multicolumn{1}{c}{ RNA platform } & \multicolumn{1}{c}{ Viral IRES (nucleotide number of original virus) } \\
\hline \multirow{2}{*}{ pCrPV-EMCV } & CrPV IGR-IRES (6025 6213) - MCS1 (EcoRI-ClaI-MluI-SacI) - EMCV 5'UTR (1 833) - MCS2 (EcoRV-SalI-PacI-SacII) - \\
& SV40 late polyadenylation signal sequence (1535 1755) \\
pMA-CVB3-EMCV & Poly(A)50 - CVB3 5’UTR (1 742) + ATG GCA GCT CAA + MCS1 (EcoRI-ClaI-MluI-SacI) - EMCV 5'UTR (1 833) - \\
& MCS2 (EcoRV-SalI-PacI-SacII) - CVB3 3'UTR (7298 7400) - Poly(A)50 \\
\hline
\end{tabular}


A

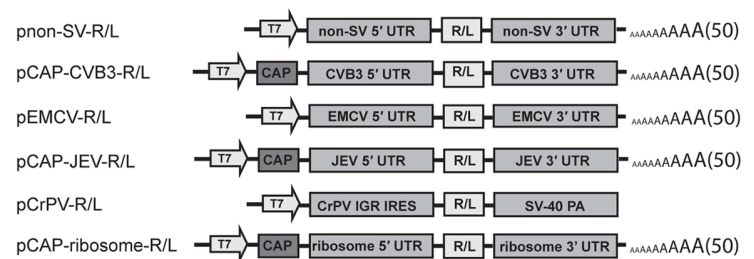

B

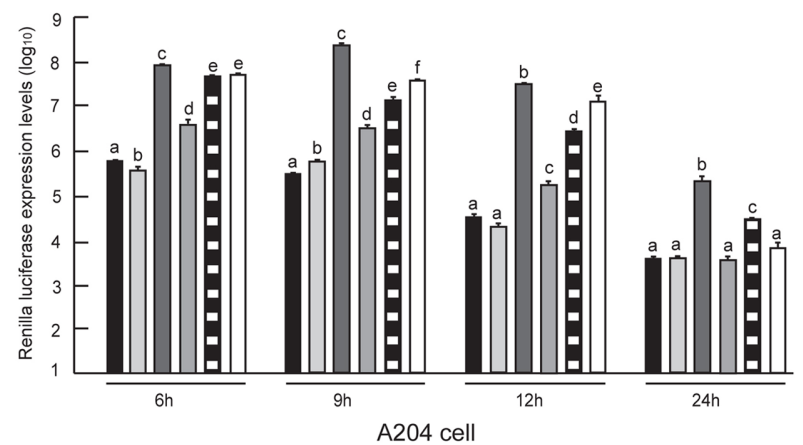

C

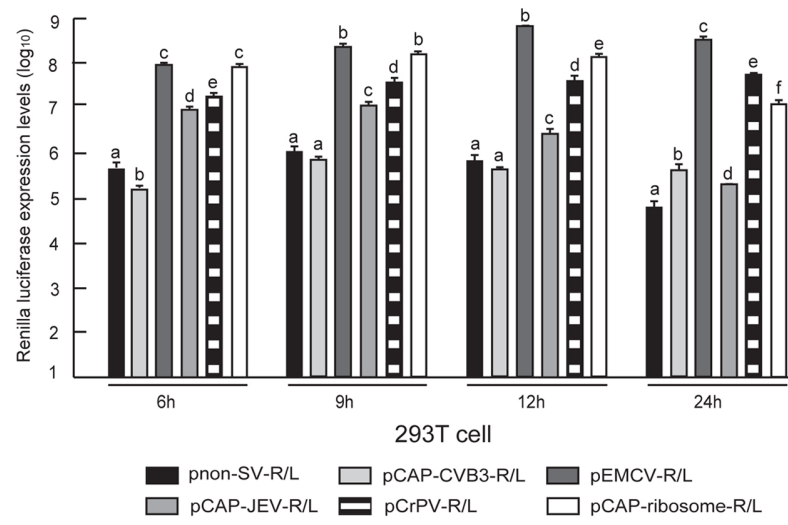

Fig. 1. Comparisons of viral internal ribosome entry site (IRES)-dependent translation efficiency using Renilla luciferase $(\mathrm{R} / \mathrm{L})$ gene expression.

(A) The gene structures of each RNA expression platform are shown as outline diagrams. Key: pnonSV-R/L, Sindbis virus IRES controls the expression of Renilla luciferase (R/L); pCAP-CVB3-R/L, cap addition at the $5^{\prime}$ end of the CVB3 IRES controls the expression of $\mathrm{R} /$ L; pEMCV-R/L, encephalomyocarditis virus (EMCV) IRES controls the expression of $\mathrm{R} / \mathrm{L}$; pCAP-JEV-R/L, cap addition at the $5^{\prime}$ end of the JEV IRES controls the expression of $\mathrm{R} / \mathrm{L}$; $\mathrm{pCrPV}-\mathrm{R} / \mathrm{L}$, cricket paralysis virus (CrPV) IGR IRES controls the expression of $\mathrm{R} / \mathrm{L}$; pCAP-ribosome- $\mathrm{R} / \mathrm{L}$, cap addition at the $5^{\prime}$ end of the CureVac company-developed ribosome UTR controls the expression of $\mathrm{R} / \mathrm{L}$ (used as a positive control). The detailed sequences and origins are shown in Table 1 and Fig. S1. The plasmids shown in (A) were transcribed into RNAs by in vitro transcription. These RNAs were transfected into human A204 muscle cells (B) and human 293T embryonic kidney cells (C), to compare R/L expression levels at 6, 9, 12 , and $24 \mathrm{~h}$ after transfection. Differences between groups were assessed by the Kruskal-Wallis test, followed by the Bonferroni posthoc test for comparing multiple treatments; different letters indicate statistically significant differences between groups. Each group had 3 wells. All samples were analyzed independently three times.
A

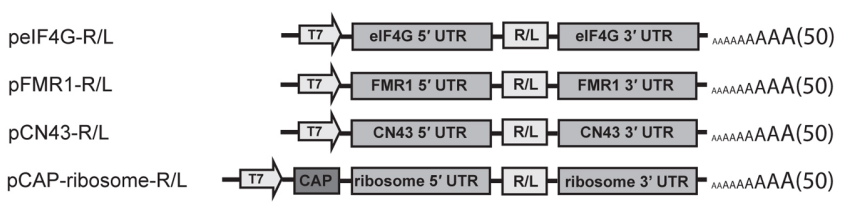

B

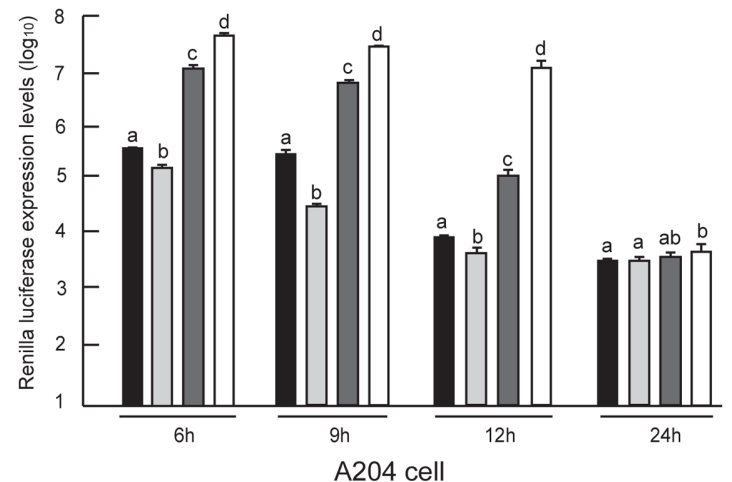

C

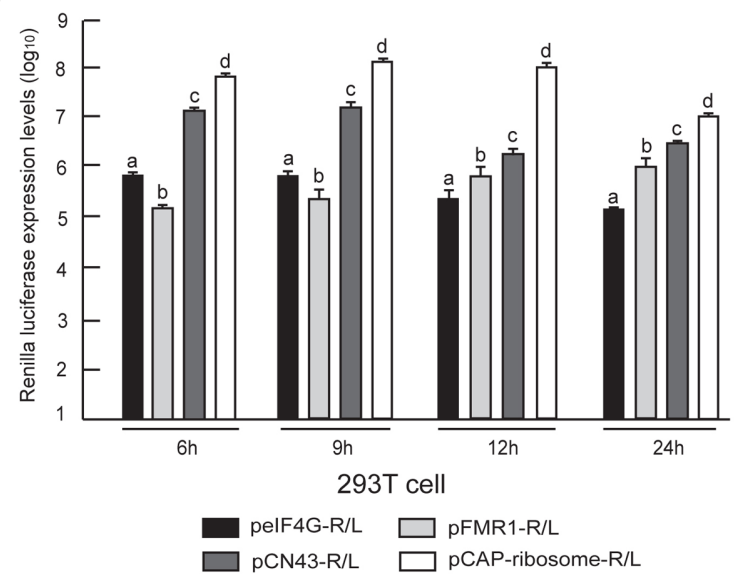

Fig. 2. Comparison with cellular IRES-dependent translation efficiency using $\mathrm{R} / \mathrm{L}$ expression.

(A) The gene structures of each RNA expression platform are shown as diagrams. Key: peIF4G-R/L, eukaryotic initiation factor $4 \mathrm{G}$ (eIF4G) IRES controls the expression of R/L; pFMR1-R/L, Fragile X mental retardation gene (FMR1) IRES controls the expression of R/L; pCN43-R/L, connexin43 (CN43) IRES controls the expression of R/L; pCAP-ribosome-R/L, cap addition at the $5^{\prime}$ end of the CureVac company-developed ribosome untranslated region (UTR) controls the expression of $\mathrm{R} / \mathrm{L}$ (used as a positive control). The detailed sequences and origins are shown in Table 2 and Fig. S1. The plasmids shown in (A) were transcribed into RNAs in vitro. These RNAs were transfected into human A204 muscle cells (B) and human 293T embryonic kidney cells (C), to compare R/L expression levels at 6, 9, 12 , and $24 \mathrm{~h}$ after transfection. Differences between groups were assessed by the Kruskal-Wallis test, followed by the Bonferroni posthoc test for comparing multiple treatments; different letters indicate statistically significant differences between groups. Each group had 3 wells. All samples were analyzed independently three times. 
gene to compare expression efficiency between A204 and 293T cells (termed peIF4G-R/L, pFMR1-R/L, and pCN43$\mathrm{R} / \mathrm{L}$, respectively) (Fig. 2A).

We found that $\mathrm{pCN} 43-\mathrm{R} / \mathrm{L}$ showed higher expression levels compared with pFMR1-R/L and peIF4G-R/L. However, the expression efficiency of $\mathrm{pCN} 43-\mathrm{R} / \mathrm{L}$ was lower than that of pCAP-ribosome-R/L, which exhibits cap-dependent translation and was used as the control, in all tested cells

A

pCVB3-R/L

PMA-CVB3-R/L
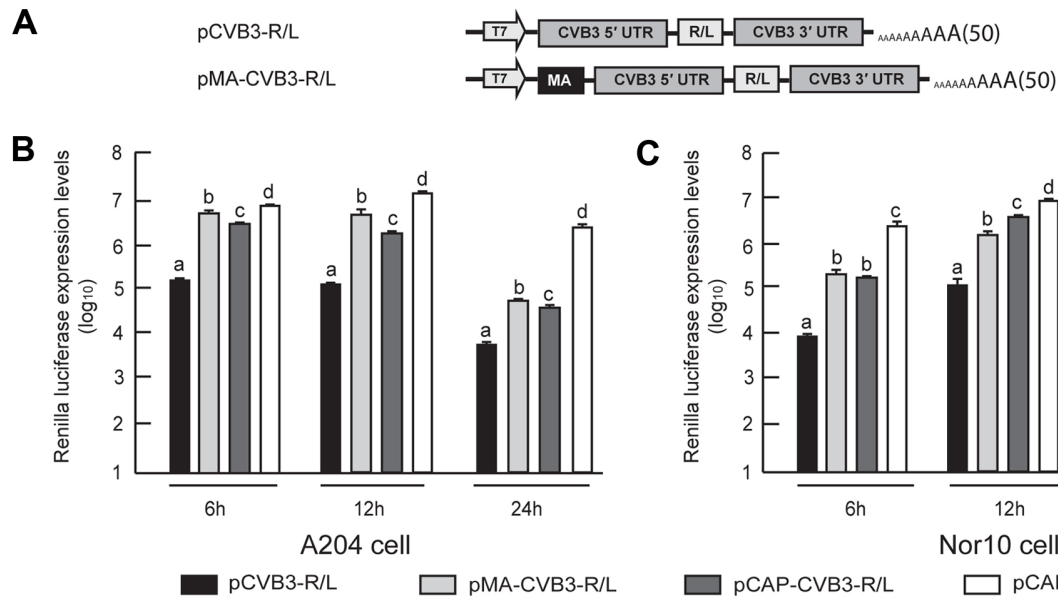

C

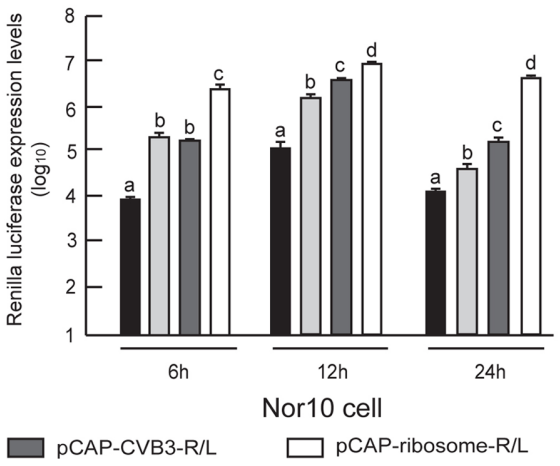

D

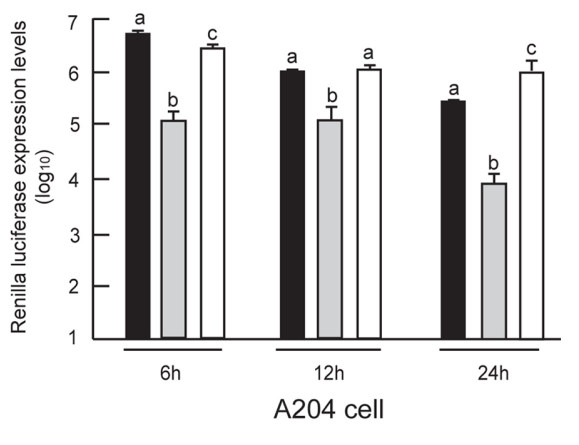

E

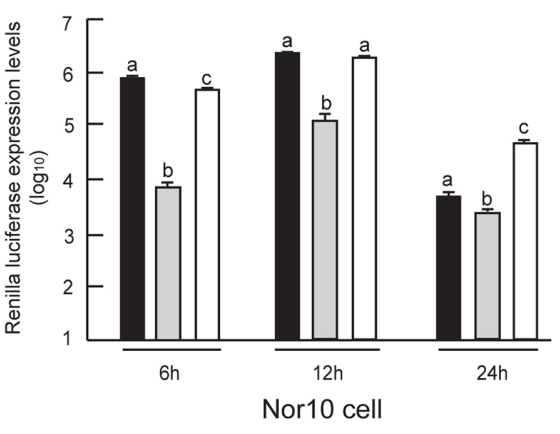

DCrPV-R/L

$\square$ pMA-CrPV-R/L

$\square$ pCAP-ribosome-R/L

F

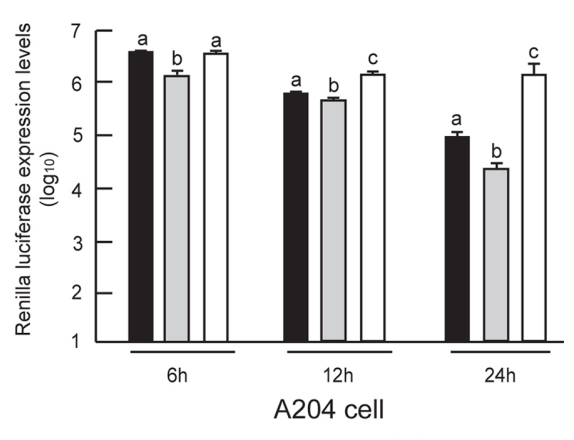

G

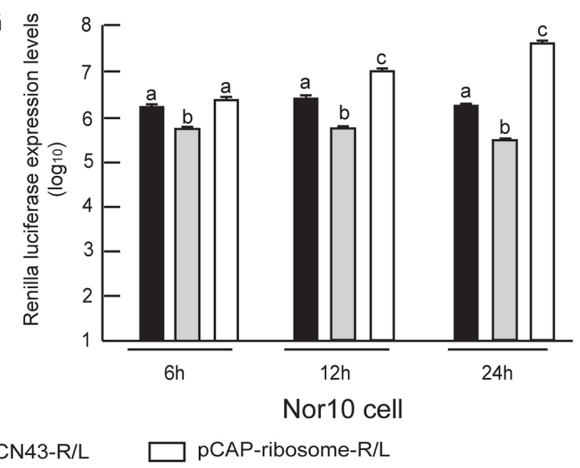

Fig. 3. Effect of the addition of a cap or poly(A) tail at the 5' end of IRESs on the level of IRES-dependent translation.

(A) The gene structures of each RNA expression platform are shown as outline diagrams. Key: pCVB3-R/L, CVB3 IRES controls the expression of $\mathrm{R} / \mathrm{L}$; pMA-CVB3-R/L, 50 adenosine monophosphates (called poly(A)) at the 5' end of the CVB3 IRES controls the expression of R/L; pCAP-CVB3$\mathrm{R} / \mathrm{L}$, cap addition at the $5^{\prime}$ end of the CVB3 IRES controls the expression of R/L; pCAP-ribosome-R/L: cap addition at the 5' end of the CureVac company-developed ribosome UTR controls the expression of R/L (used as a positive control). The detailed sequences and origins are shown in Table 1 and Fig. S1. The plasmids shown in (A) were transcribed into RNAs in vitro. These RNAs were transfected into human A204 muscle cells and mouse Nor10 muscle fibroblasts (B-G), to compare R/L expression levels at 6, 12, and $24 \mathrm{~h}$ after transfection. Differences between groups were assessed by the Kruskal-Wallis test, followed by the Bonferroni post-hoc test for comparing multiple treatments; different letters indicate statistically significant differences between groups. Each group had 3 wells. All samples were analyzed independently three times. 
(Figs. 2B and 2C). Although previous articles reported that some cellular IRES-dependent translation systems showed a higher or similar expression efficiency compared with the activity of viral IRESs, such as EMCV [21, 25, 26], the cellular IRESs tested in our experiments did not show better expression activity in human muscle and embryonic kidney cell lines compared with cap-dependent translation by $\mathrm{pCAP-ribosome-R/L}$. This means that the IRES expression activity may be dependent on cell type or cellular conditions. It should be noted that, if we aim to develop an RNA expression platform as a vaccine or genedelivery vehicle for human cells, expression efficiency in muscle cells would be more important than in other cell types. Therefore, these cellular IRESs would not be suitable for the development of an RNA expression platform.

\section{Addition of a Poly(A) Tail at the 5' end of the CVB3 IRES Increases the Level of IRES-Dependent Translation}

The $5^{\prime}$ end of the CVB3 genome was covalently linked with a short viral peptide (22 amino acids) named VPg (for virus protein genome linked), which is originally encoded by the viral 3B gene [27-29]. Here, to replace the effect of VPg in $C V B 3$, we added a cap using the ARCA reaction (pCAPCVB3) or 50 adenosine monophosphates (called poly(A) or indicated as MA) at the $5^{\prime}$ end of the CVB3 IRES (pMA-
CVB3), instead of VPg (Fig. 3A). Interestingly, the addition of poly(A) at the $5^{\prime}$ end of the CVB3 IRES (pMA-CVB3-R/L) increased the efficiency of IRES-dependent translation compared with the CVB3 IRES without poly(A) (pCVB3-R/L). Moreover, the addition of poly(A) (pMA-CVB3-R/L) led to similar or better expression levels compared with the capbinding CVB3 IRES (pCAP-CVB3-R/L) (Figs. 3B and 3C). However, this poly(A) effect of increasing translation efficiency did not apply to other IRESs, in which the addition of poly(A) at the 5' end of the CrPV IRES (pMACrPV-R/L) and CN43 IRES (pMA-CN43-R/L) decreased, rather than increased, expression levels compared with CrPV and CN43 IRESs without poly(A) (pCrPV-R/L and pCN43-R/L) (Figs. 3D-3G).

\section{The IRES Activities of EMCV and CrPV Are Higher than Those of Other Viruses in a Single-RNA Expression Platform}

To select the IRES with the highest activity in a singleRNA expression platform, we compared pMA-CVB3-R/L, $\mathrm{pCN} 43-\mathrm{R} / \mathrm{L}$, pEMCV-R/L, and pCrPV-R/L with pCAPribosome-R/L, which was used as a positive control. pEMCV-R/L showed the highest expression level in A204 and 293T cells compared with the other IRESs. pCrPV-R/L exhibited the second-highest expression levels. The
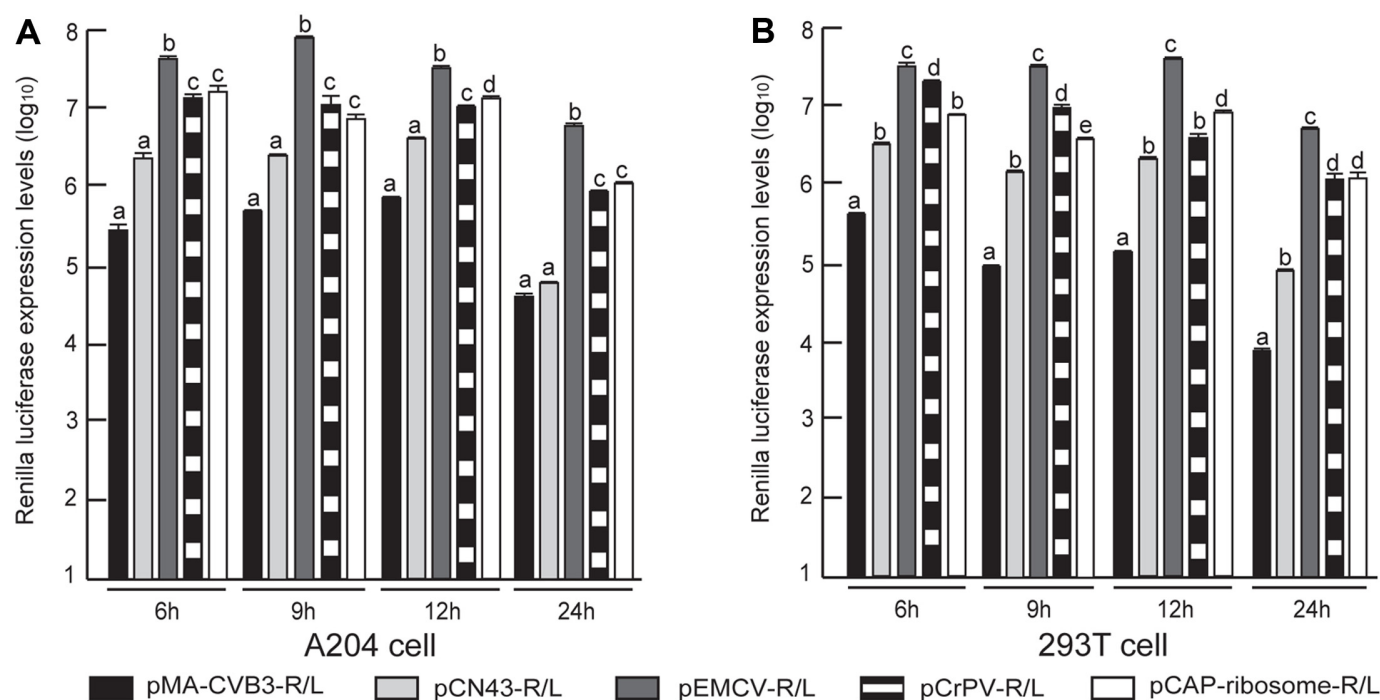

Fig. 4. EMCV and CrPV IRES showed the highest expression level compared with the activities of other IRESs in single-RNA expression platforms.

pCAP-CVB3-R/L, pCN43-R/L, pEMCV-R/L, pCrPV-R/L, and pCAP-ribosome-R/L (used as a positive control) were transcribed into RNAs in vitro. These RNAs were transfected into human A204 muscle cells (A) and human 293T embryonic kidney cells (B), to compare R/L expression levels at 6, 9, 12, and $24 \mathrm{~h}$ after transfection. Differences between groups were assessed by the Kruskal-Wallis test, followed by the Bonferroni post-hoc for comparing multiple treatments; different letters indicate statistically significant differences between groups. Each group had 3 wells. All samples were analyzed independently three times. 
A
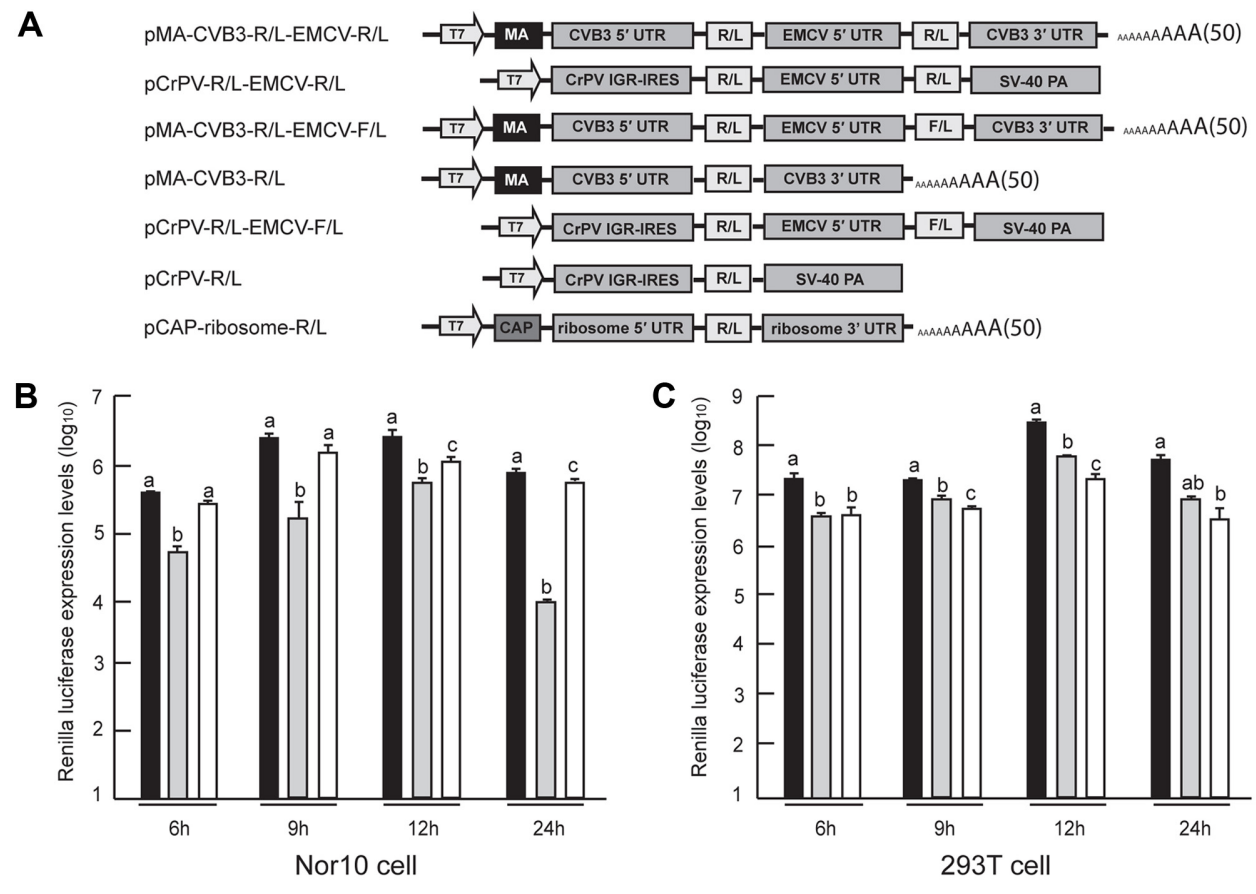

pMA-CVB3-R/L-EMCV-R/L

pCrPV-R/L-EMCV-R/L

pCAP-ribosome-R/L
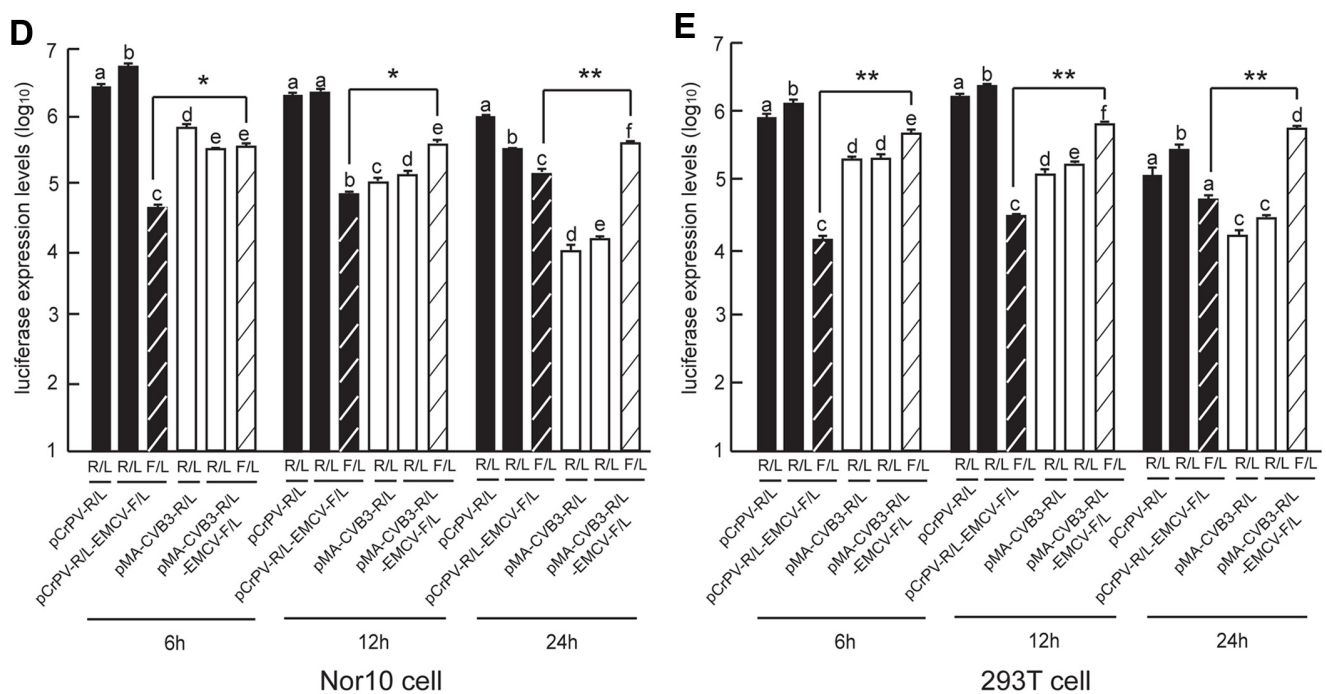

Fig. 5. The multi-RNA expression platform combined with IRESs obtained from poly(A) addition to CVB3 (MA-CVB3) and EMCV showed the highest expression level.

(A) The gene structures of each RNA expression platform are shown as outline diagrams. Key: pMA-CVB3-R/L-EMCV-R/L, poly(A) additions at the $5^{\prime}$ end of the CVB3 IRES plus EMCV IRES control the expression of R/L; pCrPV-R/L-EMCV-R/L, CrPV IRES, and EMCV IRES control the expression of R/L; pMA-CVB3-R/L-EMCV-F/L, poly(A) addition at the $5^{\prime}$ end of a CVB3 IRES controls the expression of R/L coupled with an EMCV IRES controlling the expression of firefly luciferase (F/L); pMA-CVB3-R/L, poly(A) addition at the $5^{\prime}$ end of a CVB3 IRES controls the expression of R/L; pCrPV-R/L-EMCV-F/L, CrPV IRES controls the expression of R/L combined with an EMCV IRES controlling the expression of $\mathrm{F} / \mathrm{L}$; pCrPV-R/L, CrPV IRES controls the expression of R/L; pCAP-ribosome-R/L, cap addition on the $5^{\prime}$ end of the CureVac companydeveloped ribosome UTR controls the expression of R/L (used as a positive control). The detailed sequences and origins are shown in Table 3 and Fig. S1. The plasmids shown in (A) were transcribed into RNAs in vitro. These RNAs were transfected into mouse Nor10 muscle fibroblasts (B, D) and human 293T embryonic kidney cells (C, E), to compare R/L and F/L expression levels at 6, 9, 12, and $24 \mathrm{~h}$ after transfection. Differences between groups were assessed by the Kruskal-Wallis test, followed by the Bonferroni post-hoc test for comparing multiple treatments; different letters indicate statistically significant differences between groups. Each group had 3 wells. All samples were analyzed independently three times. 
expression efficiency of $\mathrm{pCrPV}-\mathrm{R} / \mathrm{L}$ was similar to, or a little lower than, that of pCAP-ribosome-R/L (Figs. 4A and $4 \mathrm{~B})$. Of note, the IRES in $\mathrm{pCrPV}-\mathrm{R} / \mathrm{L}$ originates from the CrPV IGR gene (Table 1, Figs. 1A and S1). Thus, the first amino acid added by CrPV IGR IRES-dependent translation is alanine, and not methionine, which is added by other IRESs and by canonical cap-dependent translation. This is because of the structural characteristics of the IRES of CrPV IGR [19].

\section{Multi-RNA Expression Platforms Developed by Combining} Viral IRESs Show the Highest Expression Levels

Based on the results described above, we selected three viral IRESs derived from CrPV (pCrPV), CVB3 with poly(A) addition (pMA-CVB3), and EMCV (pEMCV), to develop a multi-RNA expression platform that combines two different viral IRESs in one RNA backbone (Fig. 5A). First, we inserted the R/L gene under the control of two viral IRESs, pMA-CVB3-R/L-EMCV-R/L and pCrPV-R/LEMCV-R/L, to compare the expression level with that of pCAP-ribosome-R/L, which was used as a system with canonical cap-dependent translation. Based on the singleRNA expression results (Figs. 1 and 4), we expected that the combined IRESs derived from $\mathrm{CrPV}$ and EMCV ( $\mathrm{pCrPV}-\mathrm{R} / \mathrm{L}-\mathrm{EMCV}-\mathrm{R} / \mathrm{L}$ ) would yield a higher expression level than did the combined IRESs of MA-CVB3 and EMCV (pMA-CVB3-R/L-EMCV-R/L), because the expression level of $\mathrm{pCrPV}-\mathrm{R} / \mathrm{L}$ was higher than that of $\mathrm{pMA}-\mathrm{CVB} 3-\mathrm{R} / \mathrm{L}$ (Fig. 4). Surprisingly, pMA-CVB3-R/L-EMCV-R/L showed an expression level that was much higher than that of pCrPV-R/L-EMCV-R/L, and even higher than that of pCAP-ribosome-R/L, in Nor10 and 293T cells (Figs. 5B and 5C).

To investigate the activity of each IRES in a multi-RNA expression platform, we inserted the $\mathrm{R} / \mathrm{L}$ gene under the control of the IRESs derived from CrPV and MA-CVB3, and the $\mathrm{F} / \mathrm{L}$ gene under the control of the IRESs derived from EMCV (pMA-CVB3-R/L-EMCV-F/L and pCrPV-R/ $\mathrm{L}-\mathrm{EMCV}-\mathrm{F} / \mathrm{L}$ ), to compare the expression of different reporter genes by single- and multiple-RNA expression platforms (Fig. 5A). The expression of R/L from pCrPV-R/ L-EMCV-F/L and pMA-CVB3-R/L-EMCV-F/L was not significantly different from that observed from $\mathrm{pCrPV}-\mathrm{R} / \mathrm{L}$ and pMA-CVB3-R/L. However, the expression of $\mathrm{F} / \mathrm{L}$ regulated by the EMCV IRES was higher in pMA-CVB3-R/ L-EMCV-F/L than it was in pCrPV-R/L-EMCV-F/L in Nor10 and 293T cells (Figs. 5D and 5E). This suggests that the CrPV IRES interferes with the expression of the EMCV

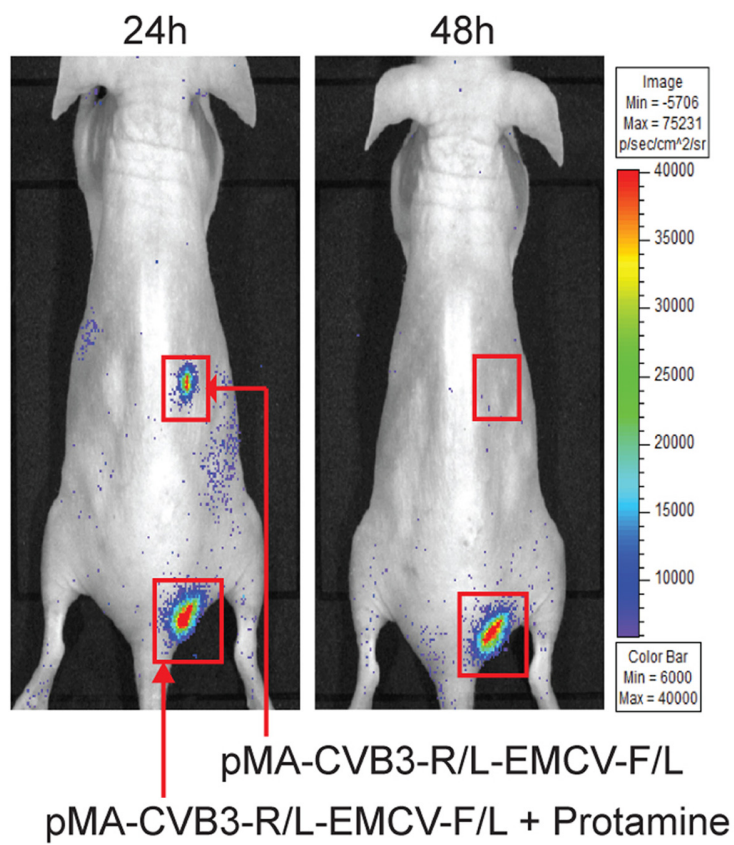

Fig. 6. RNA expression platforms expressed the reporter gene in the mouse back muscle.

At 24 and $48 \mathrm{~h}$ after the injection of pMA-CVB3-R/L-EMCV-F/Lderived RNA with or without protamine into the back muscle of mice, luciferase expression activity was confirmed using an in vivo imaging system.

IRES, whereas MA-CVB3 IRES does not.

RNA Expression Platforms Constructed Using Viral IRESs Can Express Reporter Genes in the Mouse In Vivo

As reported above, the RNA expression platforms developed in this study effectively expressed a foreign reporter gene in human and mouse cell lines. However, this does not guarantee in vivo expression when the RNA platform is injected into mice. To test this, we injected pMA-CVB3-R/L-EMCV-F/L-derived RNA into the back muscle of immunosuppressed nude mice and detected F/L expression levels at 24 and $48 \mathrm{~h}$ after injection (Fig. 6). In addition, previous reports showed that a proper ratio of mixing between the polybasic protein protamine and RNA can stabilize the RNA [30,31]. Therefore, we investigated the effects of protamine addition on the retention of RNA in vivo. We injected pMA-CVB3-R/L-EMCV-F/L-derived RNA with or without protamine. As expected, the RNA formulated with protamine maintained the expression of the F/L gene for up to $48 \mathrm{~h}$ after injection, whereas RNA without protamine yielded expression of the F/L gene for only $24 \mathrm{~h}$ after injection (Fig. 6). 


\section{Discussion}

Increasingly, RNA-based therapeutic drugs and prophylactic vaccines have been developed for treating human diseases [3]. For example, the hemagglutinin gene of the influenza virus, the premembrane and envelope genes of the Zika virus, the envelope gene of the dengue virus, the glycoproteins of the Ebola and rabies viruses, and the fusion protein gene of the respiratory syncytial virus have been delivered by RNA-based expression platforms into mice, ferrets, swine, and even humans, to confirm the potential of prophylactic vaccines [32-40]. Moreover, several cancer-specific antigens, including neoantigens and host factors, have been delivered by RNA expression platforms for the application of immunotherapy to the treatment of colon carcinomas, melanomas, and prostate cancers [10, 41-43]. Most of these reports using RNA expression platforms clearly showed a good induction of both humoral and cellular immune responses [2, 3, 8, 9]. Thus, RNA expression platforms can be applied to the delivery of both therapeutic and prophylactic vaccines. However, there are two major hurdles in the development of RNA-based drugs, including vaccines. First, the manner in which the chosen RNA sequence is formulated and delivered is important to circumvent RNase-dependent degradation and to increase the efficiency of delivery into cells, because these enzymes are ubiquitously present in extracellular environments, such as the skin, and even in intracellular environments [8,44]. Therefore, conjugation with lipid nanoparticles (LNPs), cationic nanoemulsions (CNEs), nanostructured lipid carriers (NLCs), and positively charged proteins (such as protamines) have been used to protect against degradation by RNases, to increase delivery efficiency into cells, and to stabilize RNA expression platforms in harsh extracellular and intracellular environments [30, $38,43,45,46]$. Second, RNA expression platforms are very limited. Recently developed RNA expression platforms have used cap-dependent translation in self-replicon-based or non-replicon-based conventional RNA platforms [4, 10]. CureVac, a biopharmaceutical company, has developed a non-replicon-based conventional RNA platform (pCAPribosome) that carries the GOI between modified 5' and 3' UTRs of the gene encoding the human ribosomal protein, and addition of the "cap," a 7-methyl-guanosine residue, to the 5' UTR and of poly(A)-poly C-specific histone stem loop sequences to the $3^{\prime}$ UTR is necessary [7]. Here, we used this pCAP-ribosome as a positive control and compared the expression efficiency of various IRESs from viruses and cellular genes that did not require a capping reaction to express the GOI.

Among the various viral and cellular IRESs studied here, viral IRESs, especially EMCV IRES (pEMCV), showed the highest expression efficiency; even higher than that of pCAP-ribosome, which was used as a positive control. CrPV IRES (pCrPV) also showed high expression levels, which were at least similar to those of pCAP-ribosome. The EMCV IRES is a class II IRES and CrPV IRES is a class IV IRES. Although the CN43 IRES showed the highest expression efficiency among the cellular IRESs, not all cellular IRESs showed a higher expression level compared with pCAP-ribosome. This result is reasonable given that most cellular IRESs generally start to be translated in cells in response to special stress conditions [47]. We found that the expression efficiency of virus-derived IRES-dependent translation was similar to, or better than, that of capdependent translation in the human muscle cell line A204 and the human embryonic kidney cell line 293T. This suggests that virus-derived IRESs, especially those from EMCV and CrPV, can be used to develop new RNA expression platforms. Note that the $5^{\prime}$ end of the CVB3 genome is covalently linked to a 22-amino-acid peptide named VPg [45], which plays a role in viral replication, but not in translation [27]. However, according to our results (Fig. 3), pCAP-CVB3, which is linked to a cap at the $5^{\prime}$ end of pCVB3-derived RNA instead of the VPg peptide, showed a higher expression level than did pCVB3, which has the $5^{\prime}$ end of CVB3-derived RNA without a cap, suggesting that capping can protect against RNA degradation or increase translational efficiency. Therefore, we added poly(A) (50 nucleotides) at the $5^{\prime}$ end of the CVB3 $5^{\prime}$ UTR (termed pMA-CVB3 here), which showed similar expression levels compared with pCAP-CVB3. This poly(A) sequence added at the $5^{\prime}$ end helped increase the efficiency of the CVB3 IRES because it might contribute to the protection of the cloverleaf structure (domain I) of the CVB3 5' UTR [48], or the generation of a ribonucleoprotein complex composed of both canonical translation initiation factors and IRES trans-acting factors from viral and cellular proteins, to control viral replication and translation $[49,50]$. However, such addition of poly(A) at the $5^{\prime}$ end did not increase translational efficiency in all IRESs studied here. In contrast with the CVB3 IRES, the addition of a poly(A) tail at IRESs from $\mathrm{CrPV}$ and $\mathrm{CN} 43$ interrupted translation. Therefore, the effect of the addition of a poly(A) sequence at the $5^{\prime}$ end might be limited to the CVB3 IRES, for practical purposes.

One of the unique features of IRES-dependent translation is that it starts in the middle of the RNA expression backbone, whereas cap-dependent translation must begin 
near the $5^{\prime}$ end of the RNA, via recognition of the cap [15, $16,18]$. Using this characteristic of IRESs, we developed a multiexpression RNA platform using the IRESs from CVB3, CrPV, and EMCV (termed pMA-CVB3-EMCV and $\mathrm{pCrPV}-\mathrm{EMCV})$. The comparison of each viral IRES revealed that the translation efficiency of EMCV was the highest, followed by that of CrPV and, finally, by that of MA-CVB3. However, the pMA-CVB3-R/L-EMCV-R/L construct showed the highest expression level compared with $\mathrm{pCrPV}-\mathrm{R} / \mathrm{L}$ EMCV-R/L and pCAP-ribosome, which was used as a positive control. To investigate this result further, we inserted different reporter genes into two different IRESs, pMA-CVB3-R/L-EMCV-F/L and pCrPV-R/L-EMCV-F/L. The expression levels of $\mathrm{R} / \mathrm{L}$ were not significantly different between multi- and single-expression platforms. In contrast, the study of the expression level of $\mathrm{F} / \mathrm{L}$ under the control of EMCV IRES showed that pMA-CVB3-R/LEMCV-F/L exhibited higher expression of $\mathrm{F} / \mathrm{L}$ than did pCrPV-R/L-EMCV-F/L. This suggests that CrPV IRES (class IV) might interfere with the function of EMCV IRES (class II), but not of CVB3 IRES (class I). However, the detailed mechanism underlying this process requires further study.

The pMA-CVB3-EMCV-derived RNA could also express the GOI in a mouse. In particular, the inclusion of protamine led to the persistence of its expression levels to $48 \mathrm{~h}$ after injection, whereas that of naked RNA (not formulated with protamine) persisted to only $24 \mathrm{~h}$ after injection. This suggests that supplementation with protamine or with other lipid-derived RNA carriers, such as LNPs, CNEs, and NLCs, might be required for the delivery of RNA expression platforms in vivo.

We developed new RNA expression platforms using viral IRESs, especially those from CVB3, CrPV, and EMCV. Moreover, we found that the addition of poly(A) sequences at the $5^{\prime}$ and $3^{\prime}$ ends of the CVB3 genome increased translation efficiency and RNA stability. In addition, we constructed a multi-RNA expression platform in a singleRNA backbone that could express the same or a different GOI under the control of different viral IRESs. None of the RNA expression platforms developed here required a capping reaction. Thus, compared with cap-dependent RNA expression platforms, our RNA expression platform is an efficient and convenient way to apply therapeutic and prophylactic vaccines.

\section{Acknowledgment}

This work was supported by the Ministry of Health \&
Welfare, Republic of Korea (HI15C2955), and the Basic Science Research Program through the NRF funded by the Ministry of Science, ICT \& Future Planning (NRF2015M3A9B5030157).

\section{Conflict of Interest}

The authors have no financial conflicts of interest to declare.

\section{References}

1. Wolff JA, Malone RW, Williams P, Chong W, Acsadi G, Jani A, et al. 1990. Direct gene transfer into mouse muscle in vivo. Science 247: 1465-1468.

2. Marć MA, Domínguez-Álvarez E, Gamazo C. 2015. Nucleic acid vaccination strategies against infectious diseases. Expert. Opin. Drug Deliv. 12: 1851-1865.

3. Sahin U, Karikó K, Türeci Ö. 2014. mRNA-based therapeutics-developing a new class of drugs. Nat. Rev. Drug Discov. 13: 759-780.

4. Kallen KJ, Theß A. 2014. A development that may evolve into a revolution in medicine: mRNA as the basis for novel, nucleotide-based vaccines and drugs. Ther. Adv. Vaccines 2: $10-31$.

5. Probst J, Fotin-Mleczek M, Schlake T, Thess A, Kramps T, Kallen KJ. 2012. pp. 223-245. Messenger RNA vaccines. In: Thalhamer J, Weiss R, Scheiblhofer S, editors. Gene vaccines. Vienna: Springer Verlag Wein.

6. Kallen KJ, Heidenreich R, Schnee M, Petsch B, Schlake T, Thess A, et al. 2013. A novel, disruptive vaccination technology: self-adjuvanted RNActive vaccines. Hum. Vaccin. Immunother. 9: 2263-2276.

7. Fotin-Mleczek M, Zanzinger $K$, Heidenreich R, Lorenz C, Thess A, Duchardt KM, et al. 2012. Highly potent mRNA based cancer vaccines represent an attractive platform for combination therapies supporting an improved therapeutic effect. J. Gene Med. 14: 428-439.

8. Geall AJ, Mandl CW, Ulmer JB. 2013. RNA: The new revolution in nucleic acid vaccines. Semin. Immunol. 25: 152159.

9. Schlake T, Thess A, Fotin-Mleczek M, Kallen KJ. 2012. Developing mRNA-vaccine technologies. RNA Biol. 9: 13191330.

10. Iavarone C, O'Hagan DT, Yu D, Delahaye NF, Ulmer JB. 2017. Mechanism of action of mRNA-based vaccines. Expert. Rev. Vaccines 16: 871-881.

11. Akhrymuk I, Kulemzin SV, Frolova EI. 2012. Evasion of the innate immune response: the Old World alphavirus nsP2 protein induces rapid degradation of Rpb1, a catalytic subunit of RNA polymerase II. J. Virol. 86: 7180-7191.

12. Hollidge BS, Weiss SR, Soldan SS. 2011. The role of interferon 
antagonist, non-structural proteins in the pathogenesis and emergence of arboviruses. Viruses 3: 629-658.

13. Blakqori G, Delhaye S, Habjan M, Blair CD, Sánchez-Vargas I, Olson KE, et al. 2007. La Crosse bunyavirus nonstructural protein NSs serves to suppress the type I interferon system of mammalian hosts. J. Virol. 81: 4991-4999.

14. Ngoi SM, Chien AC, Lee CG. 2004. Exploiting internal ribosome entry sites in gene therapy vector design. Curr. Gene Ther. 4: 15-31.

15. Mailliot J, Martin F. 2018. Viral internal ribosomal entry sites: four classes for one goal. Wiley Interdiscip Rev. RNA 9: $\mathrm{e} 1458$.

16. Yamamoto H, Unbehaun A, Spahn CMT. 2017. Ribosomal chamber music: toward an understanding of IRES mechanisms. Trends Biochem. Sci. 42: 655-668.

17. Pelletier J, Sonenberg N. 1988. Internal initiation of translation of eukaryotic mRNA directed by a sequence derived from poliovirus RNA. Nature 334: 320-325.

18. Kieft JS. 2008. Viral IRES RNA structures and ribosome interactions. Trends Biochem. Sci. 33: 274-283.

19. Murray J, Savva CG, Shin BS, Dever TE, Ramakrishnan V, Fernández IS. 2016. Structural characterization of ribosome recruitment and translocation by type IV IRES. Elife 5: e13567.

20. Cho A, Seok SH. 2013. Ethical guidelines for use of experimental animals in biomedical research. J. Bacteriol. Virol. 43: 18-26.

21. Wong ET, Ngoi SM, Lee CG. 2002. Improved co-expression of multiple genes in vectors containing internal ribosome entry sites (IRESes) from human genes. Gene Ther. 9: 337-344.

22. Chiang PW, Carpenter LE, Hagerman PJ. 2001. The 5\&untranslated region of the FMR1 message facilitates translation by internal ribosome entry. J. Biol. Chem. 276: 37916-37921.

23. Filley CM, Brown MS, Onderko $K$, Ray M, Bennett RE, Berry-Kravis E, et al. 2015. White matter disease and cognitive impairment in FMR1 premutation carriers. Neurology 84: 2146-2152.

24. Schiavi A, Hudder A, Werner R. 1999. Connexin43 mRNA contains a functional internal ribosome entry site. FEBS Lett. 464: 118-122.

25. Bernstein J, Sella O, Le SY, Elroy-Stein O. 1997. PDGF2/c-sis mRNA leader contains a differentiation-linked internal ribosomal entry site (D-IRES). J. Biol. Chem. 272: 9356-9362.

26. Huez I, Créancier L, Audigier S, Gensac MC, Prats AC, Prats $\mathrm{H}$, et al. 1998. Two independent internal ribosome entry sites are involved in translation initiation of vascular endothelial growth factor mRNA. Mol. Cell Biol. 18: 61786190.

27. Goodfellow I. 2011. The genome-linked protein VPg of vertebrate viruses-a multifaceted protein. Curr. Opin. Virol. 1: 355-362.

28. Sean P, Semler BL. 2008. Coxsackievirus B RNA replication: lessons from poliovirus. Curr. Top. Microbiol. Immunol. 323:
89-121.

29. Langereis MA, Feng Q, Nelissen FH, Virgen-Slane R, van der Heden van Noort GJ, Maciejewski S, et al. 2014. Modification of picornavirus genomic RNA using 'click' chemistry shows that unlinking of the VPg peptide is dispensable for translation and replication of the incoming viral RNA. Nucleic Acids Res. 42: 2473-2482.

30. Sköld AE, van Beek JJ, Sittig SP, Bakdash G, Tel J, Schreibelt G, et al. 2015. Protamine-stabilized RNA as an ex vivo stimulant of primary human dendritic cell subsets. Cancer Immunol. Immunother. 64: 1461-1473.

31. Scheel B, Teufel R, Probst J, Carralot JP, Geginat J, Radsak M, et al. 2005. Toll-like receptor-dependent activation of several human blood cell types by protamine-condensed mRNA. Eur. J. Immunol. 35: 1557-1566.

32. Petsch B, Schnee M, Vogel AB, Lange E, Hoffmann B, Voss D, et al. 2012. Protective efficacy of in vitro synthesized, specific mRNA vaccines against influenza A virus infection. Nat. Biotechnol. 30: 1210-1216.

33. Richner JM, Himansu S, Dowd KA, Butler SL, Salazar V, Fox JM, et al. 2017. Modified mRNA vaccines protect against Zika virus infection. Cell 169: 176

34. Avogadri F, Merghoub T, Maughan MF, HirschhornCymerman D, Morris J, Ritter E, et al. 2010. Alphavirus replicon particles expressing TRP-2 provide potent therapeutic effect on melanoma through activation of humoral and cellular immunity. PLoS One 5: e12670.

35. Seregin SS, Appledorn DM, McBride AJ, Schuldt NJ, Aldhamen YA, Voss T, et al. 2009. Transient pretreatment with glucocorticoid ablates innate toxicity of systemically delivered adenoviral vectors without reducing efficacy. Mol. Ther. 17: 685-696.

36. Pyankov OV, Bodnev SA, Pyankova OG, Solodkyi VV, Pyankov SA, Setoh YX, et al. 2015. A Kunjin replicon viruslike particle vaccine provides protection against Ebola virus infection in nonhuman primates. J. Infect. Dis. 212(Suppl 2): S368-S371.

37. Schnee M, Vogel AB, Voss D, Petsch B, Baumhof P, Kramps T, et al. 2016. An mRNA vaccine encoding rabies virus glycoprotein induces protection against lethal infection in mice and correlates of protection in adult and newborn pigs. PLoS Negl. Trop. Dis. 10: e0004746.

38. Brito LA, Chan M, Shaw CA, Hekele A, Carsillo T, Schaefer M, et al. 2014. A cationic nanoemulsion for the delivery of nextgeneration RNA vaccines. Mol. Ther. 22: 2118-2129.

39. Bahl K, Senn JJ, Yuzhakov O, Bulychev A, Brito LA, Hassett KJ, et al. 2017. Preclinical and clinical demonstration of immunogenicity by mRNA vaccines against $\mathrm{H} 10 \mathrm{~N} 8$ and H7N9 influenza viruses. Mol. Ther. 25: 1316-1327.

40. Alberer M, Gnad-Vogt U, Hong HS, Mehr KT, Backert L, Finak $G$, et al. 2017. Safety and immunogenicity of a mRNA rabies vaccine in healthy adults: an open-label, nonrandomised, prospective, first-in-human phase 1 clinical 
trial. Lancet 390: 1511-1520.

41. Youn H, Chung JK. 2015. Modified mRNA as an alternative to plasmid DNA (pDNA) for transcript replacement and vaccination therapy. Expert. Opin. Biol. Ther. 15: 1337-1348.

42. Diken M, Kranz LM, Kreiter S, Sahin U. 2017. mRNA: A versatile molecule for cancer vaccines. Curr. Issues Mol. Biol. 22: 113-128.

43. Kranz LM, Diken M, Haas H, Kreiter S, Loquai C, Reuter KC, et al. 2016. Systemic RNA delivery to dendritic cells exploits antiviral defence for cancer immunotherapy. Nature 534: 396-401.

44. Dickson KA, Haigis MC, Raines RT. 2005. Ribonuclease inhibitor: structure and function. Prog. Nucleic Acid. Res Mol. Biol. 80: 349-374.

45. Geall AJ, Verma A, Otten GR, Shaw CA, Hekele A, Banerjee K, et al. 2012. Nonviral delivery of self-amplifying RNA vaccines. Proc. Natl. Acad. Sci. USA 109: 14604-14609.
46. Bettinger T, Carlisle RC, Read ML, Ogris M, Seymour LW 2001. Peptide-mediated RNA delivery: a novel approach for enhanced transfection of primary and post-mitotic cells. Nucleic Acids Res. 29: 3882-3891.

47. Leppek K, Das R, Barna M. 2018. Functional $5 \not$ UTR mRNA structures in eukaryotic translation regulation and how to find them. Nat. Rev. Mol. Cell Biol. 19: 158-174.

48. Simoes EA, Sarnow P. 1991. An RNA hairpin at the extreme $5^{\prime}$ end of the poliovirus RNA genome modulates viral translation in human cells. J. Virol. 65: 913-921.

49. Andino R, Rieckhof GE, Baltimore D. 1990. A functional ribonucleoprotein complex forms around the $5^{\prime}$ end of poliovirus RNA. Cell 63: 369-380.

50. Herold J, Andino R. 2007. Poliovirus requires a precise 5' end for efficient positive-strand RNA synthesis. J. Virol. 74: 6394-400. 